\title{
The Knockdown of $\alpha$ kap Alters the Postsynaptic Apparatus of Neuromuscular Junctions in Living Mice
}

\author{
Isabel Martinez-Pena y Valenzuela, ${ }^{1}$ Mohamed Aittaleb, ${ }^{1}$ Po-Ju Chen, ${ }^{1}$ and Mohammed Akaaboune ${ }^{1,2}$ \\ ${ }^{1}$ Department of Molecular, Cellular, and Developmental Biology, and ${ }^{2}$ Program in Neuroscience, University of Michigan, Ann Arbor, Michigan 48109
}

\begin{abstract}
A muscle-specific nonkinase anchoring protein ( $\alpha$ kap), encoded within the calcium/calmodulin kinase II (camk2) $\alpha$ gene, was recently found to control the stability of acetylcholine receptor (AChR) clusters on the surface of cultured myotubes. However, it remains unknown whether this protein has any effect on receptor stability and the maintenance of the structural integrity of neuromuscular synapses in vivo. By knocking down the endogenous expression of $\alpha$ kap in mouse sternomastoid muscles with shRNA, we found that the postsynaptic receptor density was dramatically reduced, the turnover rate of receptors at synaptic sites was significantly increased, and the insertion rates of both newly synthesized and recycled receptors into the postsynaptic membrane were depressed. Moreover, we found that $\alpha$ kap shRNA knockdown impaired synaptic structure as postsynaptic AChR clusters and their associated postsynaptic scaffold proteins within the neuromuscular junction were completely eliminated. These results provide new mechanistic insight into the role of $\alpha$ kap in regulating the stability of the postsynaptic apparatus of neuromuscular synapses.
\end{abstract}

Key words: $\alpha$ kap; imaging; knockdown; nAChR dymamics; NMJ; stability

\section{Introduction}

The clustering and maintenance of a high density of nicotinic acetylcholine receptors (AChRs) at the postsynaptic membrane is a hallmark of the peripheral neuromuscular synapse, the synapse between spinal motor neurons and skeletal muscle fibers (Sanes and Lichtman, 2001; Wu et al., 2010). Several subsynaptic molecular components have been shown to be critical for the stability of the postsynaptic receptor density. For instance, the density of AChRs is significantly reduced at the synapses of mice deficient in intracellular postsynaptic components of the dystrophin glycoprotein complex such as syntrophins (Adams et al., 2000), or $\alpha$-dystrobrevin (Grady et al., 1999). Mutation of other postsynaptic proteins such as rapsyn, dok7, low-density lipoprotein receptor-related protein 4 (Lrp4), or muscle-specific receptor tyrosine kinase (MusK), cause failure of formation of synaptic clusters (Gautam et al., 1995; Glass et al., 1996; Weatherbee et al., 2006; Kim et al., 2008; Zhang et al., 2008). Recent work from our laboratory has shown that a muscle-specific nonkinase anchoring protein ( $\alpha \mathrm{kap})$ also controls the stability of AChR clusters on the surface of cultured C2C12 myotubes (Mouslim et al., 2012). It remains unknown, however, whether $\alpha$ kap has any effect on the stability of the neuromuscular junction (NMJ) of living mice.

\footnotetext{
Received Sept. 23, 2014; revised Jan. 30, 2015; accepted Feb. 12, 2015.

Author contributions: M. Akaaboune designed research; I.M.-P.y.V. and P.-J.C. performed research; M. Aittaleb contributed unpublished reagents/analytic tools; I.M.-P.y.V., M. Aittaleb, and M. Akaaboune analyzed data; I.M.-P.y.V., M. Aittaleb, and M. Akaaboune wrote the paper.

This work was supported by the National Institutes of Health. We thank Dr. Richard Hume, Dr. Chakib Mouslim, and Jacob Menke for their critical help on the manuscript.

The authors declare no competing financial interests.

Correspondence should be addressed to Dr. Mohammed Akaaboune, Department of Molecular, Cellular, and Developmental Biology, Neuroscience Program, University of Michigan, Ann Arbor, MA 48109. E-mail: makaabou@umich.edu.

DOI:10.1523/JNEUROSCI.3951-14.2015

Copyright $\odot 2015$ the authors $\quad 0270-6474 / 15 / 355118-10 \$ 15.00 / 0$
}

$\alpha$ kap, a nonkinase protein encoded within the Camk2a gene, contains a putative transmembrane domain and an association domain but lacks the catalytic domain, and was initially identified as a molecule that targets multiple isoforms of calcium/ calmodulin-dependent protein kinase II (CaMKII) to specific subcellular locations, where they act (Bayer et al., 1996, 1998, 2002). Previous studies reported that in mature muscle cells $\alpha$ kap targets CaMKII isoforms to the sarcoplasmic reticulum, where they regulate calcium homeostasis (a process that is critical for excitation/contraction coupling), and to the nucleus, where they can regulate the nuclear transcription factor SRF (Volpe et al., 1992; Fluck et al., 2000; O'Leary et al., 2006). More recently, it was shown that CaMKII isoforms are also concentrated at NMJs, where they colocalize with AChRs at synaptic sites (Campbell and MacLennan, 1982; Damiani et al., 1995; Bayer et al., 1998; Nori et al., 2003; Martinez-Pena y Valenzuela et al., 2010), and the blockade of their enzymatic activities dramatically altered the trafficking of receptors and the steady state of the postsynaptic receptor density (Martinez-Pena y Valenzuela et al., 2010). Here we sought to examine whether the loss of function of $\alpha$ kap in skeletal muscles would impact the trafficking and stability of postsynaptic density, and the structure of NMJs in living mice. Using a loss-of-function approach, we used short hairpin RNA (shRNA) to knock down the endogenous expression of $\alpha$ kap in muscle cells and to investigate the physiological effect of $\alpha \mathrm{kap}$ on the molecular dynamics of AChRs and the maintenance of the structural integrity of the synapse. Electroporation of $\alpha$ kap shRNA was performed in mouse sternomastoid muscles. Analysis of synapses showed that the loss of function of $\alpha$ kap significantly altered the stability of AChRs and induced the disassembly of the postsynaptic apparatus of the NMJ. 


\section{Materials and Methods}

Plasmid constructs. GFP- $\alpha$ kap was generated in our laboratory using the pEGFP-C3 vector, in which alanine was mutated to lysine at position 207 (A207K) to prevent the dimerization of GFP (monomeric-GFP-C3), as described in our previous work (Mouslim et al., 2012). Rapsyn-GFP (a gift from Johnathan Cohen, Harvard Medical School, Boston, MA), $\alpha$-syntrophin, and $\alpha$-dystrobrevin GFP constructs were generated in our laboratory, as previously described (Martinez-Pena y Valenzuela et al., 2010).

The murine shRNA $\alpha$ kap construct and its scrambled version were generated as described in our previous work (Mouslim et al., 2012). The target sequences were as follows: $5^{\prime}$-GTTCAGTTAATGGAATCTTC for shRNA $\alpha$ kap; and 5'-GGTTATCTATTAGCGATTCTA for scrambled shRNA. For our initial control experiments, to verify that the sequences selected could successfully decrease $\alpha$ kap levels in vivo, the sternomastoid muscle was electroporated with either a mixture of GFP- $\alpha$ kap and shRNA $\alpha$ kap or with a mixture of GFP- $\alpha$ kap and scrambled shRNA. When muscle fibers were viewed $7 \mathrm{~d}$ later, there were many green fluorescent muscle fibers in mice electroporated with GFP- $\alpha$ kap and scrambled shRNA, but very few fluorescent fibers in muscles electroporated with GFP- $\alpha$ kap and shRNAs (data not shown), indicating that shRNA $\alpha$ kap was effective in knocking down the expression of exogenous $\alpha$ kapGFP. The specificity of shRNA $\alpha$ kap was also tested in our previous work, in which we showed that it had no effect on the expression level of three CaMKII isoforms $(\beta \mathrm{m}, \gamma$, and $\delta)$ that are expressed in muscle cells and have several domains similar to the domains of $\alpha$ kap (Mouslim et al., 2012).

For all other experiments, the identical sequences were cloned into pSuper.GFP/neo, which drives GFP expression and shRNA production from different promoters. All shRNA constructs were verified by DNA sequencing.

Electroporation of constructs into the sternomastoid muscle and confocal microscopy. Adult female mice (weight, $30 \mathrm{~g}$ ) were anesthetized by injecting intraperitoneally a mixture of $80 \mathrm{mg} / \mathrm{kg}$ ketamine and $20 \mathrm{mg} / \mathrm{kg}$ xylazine, and the sternomastoid muscle was surgically exposed. The solution containing the plasmid ( $10 \mu \mathrm{g})$ expressing shRNA $\alpha$ kap-GFP, a scrambled version of the shRNA sequence, $\alpha$ kap-GFP, rapsyn-GFP, $\alpha$-syn-GFP, $\alpha$-dbn-GFP, or GFP-CaMKII $\beta$ M was placed over the sternomastoid muscle, as described in our previous work (Bruneau and Akaaboune, 2010; Martinez-Pena y Valenzuela et al., 2010). Gold electrodes were set parallel to the muscle fibers on either side of the muscle, and then eight monopolar square-wave pulses were applied perpendicularly to the long axis of the muscle. The animal was sutured and allowed to recover in a warm chamber (Bruneau and Akaaboune, 2010). All animal usage methods were approved by the University of Michigan Committee on the Use and Care of Animals.

Receptor labeling and imaging of neuromuscular junctions of living mice. To assess the effect of the knockdown of $\alpha$ kap on the stability of the postsynaptic AChR density, the sternomastoid muscle of mice electroporated with either GFP-shRNA $\alpha$ kap or scrambled shRNA ( 4 and $7 \mathrm{~d}$ after electroporation) was bathed with a saturating dose of bungarotoxin (BTX)-Alexa Fluor $594(5 \mu \mathrm{g} / \mathrm{ml}$ for $1 \mathrm{~h})$, and the whole animal was placed on its back on the stage of a customized epifluorescence microscope, as described previously (Akaaboune et al., 1999; Martinez-Pena y Valenzuela et al., 2010; 2011). Superficial neuromuscular junctions were imaged with a water-immersion objective [ $20 \times$ UApo 0.8 numerical aperture (NA) Olympus BW51; Optical Analysis Corp.], and the fluorescence intensity was assayed using a quantitative fluorescence imaging technique, as described previously (Turney et al., 1996).

To determine the effect of shRNA $\alpha$ kap on the insertion of newly synthesized AChRs, the electroporated muscles with shRNA- $\alpha$ kap-GFP and scrambled shRNA-GFP were exposed after $4 \mathrm{~d}$ of electroporation, bathed with a saturating dose of BTX-Alexa Fluor 594 (to saturate all AChRs at superficial NMJs), and NMJs on electroporated (expressing GFP) and nonelectroporated neighboring muscle fibers were immediately imaged. Six days later, synapses were relocated and imaged again (to estimate the number of lost receptors after the initial labeling) and then bathed with the same fluorescent BTX-Alexa Fluor 594 to saturate all newly synthesized AChRs that have been inserted after the initial labeling (time 0), and the same synapses were reimaged for a third time. The fluorescence intensity of labeled AChRs at the three different views was then assayed.

To determine the effect of the shRNA $\alpha$ kap on the turnover rate of AChRs, the sternomastoid muscle of mice expressing GFP-shRNA $\alpha$ kap or scrambled GFP-shRNA $\alpha$ kap (7 d after electroporation) was labeled with a nonsaturating dose of BTX-Alexa Fluor $594(1 \mu \mathrm{g} / \mathrm{ml})$ and superficial NMJs were imaged and then reimaged $3 \mathrm{~d}$ later. The fluorescence intensity of labeled receptors at NMJs on muscles expressing shRNA scrambled and nonelectroporated muscles was assayed.

To determine the effect of shRNA $\alpha$ kap on the recycling of AChRs, receptors on the sternomastoid muscle electroporated with shRNA $\alpha$ kap or scrambled shRNA were labeled as described previously (Bruneau and Akaaboune, 2006). Briefly, receptors were labeled with biotinylated BTX (BTX-biotin; $5 \mu \mathrm{g} / \mathrm{ml}$, for $30 \mathrm{~min}$; Invitrogen) followed by a single saturating dose of streptavidin-Alexa Fluor $594(10 \mu \mathrm{g} / \mathrm{ml}, 3 \mathrm{~h})$. A second color of streptavidin was then added to the sternomastoid muscle to be sure that all biotin sites were saturated (streptavidin Alexa Fluor 647, 10 $\mu \mathrm{g} / \mathrm{ml}$, for $\sim 30 \mathrm{~min}$ ), and the NMJs were imaged. Three days later (after initial labeling), the mouse was anesthetized and imaged for a second time, then the sternomastoid muscle was bathed with streptavidin-Alexa Fluor $594(10 \mu \mathrm{g} / \mathrm{ml}$, for $1 \mathrm{~h})$ to label receptors that had lost their streptavidin tag upon their internalization and were reinserted into synaptic membrane with their BTX-biotin tag (recycled AChR pool). The same synapses were reimaged, and their fluorescence intensities were measured. Experiments showing that the dissociation of streptavidin from biotin does not occur on the surface of the muscle cells but instead inside the muscle fiber were reported in our previously published work (Bruneau et al., 2005; Bruneau and Akaaboune, 2006).

Quantitative fluorescence imaging. Images of NMJs were collected using IPLAB software and calibrated to a nonfading reference standard to compensate for spatial and temporal changes in the light source and camera between imaging sessions at different time points, as described previously (Turney et al., 1996; Akaaboune et al., 1999; Martinez-Pena y Valenzuela et al., 2011). The analysis of the fluorescence intensity of labeled AChR at the neuromuscular junction of electroporated and nonelectroporated muscles was performed using a procedure written for Matlab (MathWorks). Background fluorescence was determined by manually selecting a boundary region around each NMJ and subtracting it from the original image, and the mean of the total fluorescence intensity (which corresponds to receptor density) was measured.

Immunofluorescence and confocal microscopy. To assess the effect of shRNA $\alpha$ kap on the disassembly of the postsynaptic apparatus of NMJs, sternomastoid muscles electroporated with GFP-shRNA- $\alpha$ kap or scrambled shRNA ( $7 \mathrm{~d}$ after electroporation) were bathed with $\alpha$-BTX-Alexa Fluor $594(5 \mu \mathrm{g} / \mathrm{ml}$, for $1 \mathrm{~h})$ and fluorescein-labeled Vicia villosa lectin (VVA B4), and then perfused with $2 \%$ paraformaldehyde (PFA). The sternomastoid muscles were removed, and NMJs were imaged with a confocal scanning laser microscope (model SPE, Leica) using an HCX Plan Apochromat $100 \times$ objective (NA 1.46) and a resolution of $1024 \times$ 1024 pixels. The disassembly of the postsynaptic apparatus due to overexpression of GFP-shRNA $\alpha$ kap was assayed by the formation of holes or perforations of a synaptic AChR cluster region lacking $\alpha$-BTX-Alexa Fluor 594 staining but still containing VVA B4 lectin as a marker of original sites. The percentage of perforated synapses containing one or more perforations was then quantified in muscles treated with shRNA $\alpha$ kap, scrambled shRNA, and nonelectroporated muscles.

To assess whether postsynaptic proteins that are associated with AChRs are also affected by shRNA $\alpha$ kap, the sternomastoid muscle was electroporated with shRNA- $\alpha$ kap and $\alpha$-dystrobrevin-GFP, $\alpha$-syntrophin-GFP, rapsyn-GFP, or GFP-CaMKII $\beta$ M. Seven days later, the sternomastoid muscle was exposed, bathed with BTX-Alex Fluor 594 , and then fixed with $2 \%$ PFA. The sternomastoid muscle was removed, mounted, and scanned with a confocal microscope (SP5, Leica). The $z$-stacks were then collapsed, and the contrast was adjusted with Photoshop.

To assess whether shRNA $\alpha$ kap has any effect on the disassembly of the presynaptic nerve terminal, the sternomastoid muscle electroporated with shRNA $\alpha$ kap ( 7 and $22 \mathrm{~d}$ after electroporation) was fixed with PFA, 
and teased fiber bundles were permeabilized with a solution containing $0.2 \%$ Triton X-100 and 2\% BSA in PBS for $30 \mathrm{~min}$, bathed in a blocking solution (10\% BSA) for $30 \mathrm{~min}$, and then incubated overnight with primary monoclonal anti-SV2 and anti-neurofilament diluted at 1:500 (Developmental Studies Hybridoma Bank). Muscle cells were then bathed with Alexa Fluor 647-conjugated anti-mouse secondary antibody (Jackson ImmunoResearch) for $1 \mathrm{~h}$, mounted on a coverslip, and imaged with a Leica SP5 confocal microscope.

Pull down and Western blotting. To determine whether $\alpha$ kap forms a complex with AChRs, the sternomastoid muscle was removed, homogenized on ice in a buffer containing 50 mm HEPES, pH 7.4, 2 mM EDTA, $150 \mathrm{~mm} \mathrm{NaCl}, 1 \% \mathrm{NP}-40,0.25 \%$ sodium deoxycholate, and protease inhibitors. Total AChRs were pulled down by incubating cell lysates with BTX-biotin for $1 \mathrm{~h}$ followed by overnight incubation with NeutrAvidin beads (Thermo Fisher Scientific). The beads were collected by centrifugation and washed in PBS four times. The bound proteins were released by boiling in reducing $4 \times$ lithium dodecyl sulfate buffer (Invitrogen), and then separated by $12 \%$ SDS-PAGE and transferred onto a polyvinylidene fluoride membrane, as described previously (Mouslim et al., 2012). Membranes were then incubated with mouse anti- $\alpha$ kap (1:2000; clone A1, Santa Cruz Biotechnology) diluted in blocking buffer (2\% fat-free milk in PBS) or rat anti-AChR $\alpha$ MAB210 (1:5000; Covance) overnight at $4^{\circ} \mathrm{C}$. After extensive washing, the membranes were then incubated with secondary HRP-conjugated antibodies (1:10,000; Jackson ImmunoResearch) and developed using SuperSignal West Femto Maximum Sensitivity Substrate or West Pico (Thermo Fisher Scientific).

\section{Results}

The knockdown of $\alpha$ kap significantly reduced the density of postsynaptic acetylcholine receptors in living mice

Our recent work showed that $\alpha$ kap is able to protect AChRs from degradation in both cultured muscle cells and heterologous HEK293T cells (Mouslim et al., 2012). Here we asked whether $\alpha$ kap controls the stability of the postsynaptic receptors at the NMJ of living animals. As a first step, we examined whether $\alpha$ kap is expressed and forms complexes with AChRs in sternomastoid muscles of living mice. Lysates from sternomastoid muscles were incubated with BTX-biotin to label AChR, and then AChR-BTXbiotin complexes were isolated with NeutrAvidin-coated beads. The complex was subjected to Western blot analysis with anti$\operatorname{AChR} \alpha$ and anti- $\alpha$ kap antibodies. We found that $\alpha$ kap was pulled down with $\mathrm{AChR} \alpha$ (Fig. $1 A$ ), indicating that AChRs are present in the same complex as $\alpha$ kap. Next, we asked whether the knockdown of endogenous expression of $\alpha$ kap has any effect on the stability of AChRs at the NMJ of living mice. This was examined by electroporating the sternomastoid muscle fibers with a single plasmid (GFP-shRNA $\alpha$ kap) expressing GFP driven by the PGK promoter and shRNA directed against $\alpha$ kap driven by the $\mathrm{H} 1$ promoter. At 4 and $7 \mathrm{~d}$ after plasmid electroporation, AChRs were labeled with BTX-594 (Fig. 1B), and the density of AChR in green fluorescent fibers (electroporated) and neighboring nonfluorescent fibers (nonelectroporated) were compared (Fig. $1 C, D)$. As a control for off-target effects of shRNA, a plasmid containing a scrambled version of the $\alpha$ kap shRNA sequence (scrambled GFP-shRNA $\alpha$ kap) was electroporated into the sternomastoid muscle of mice. At $4 \mathrm{~d}$ after electroporation, the total fluorescence of AChRs was decreased by $8 \%$ (mean \pm SD, $92 \pm$ $15 \% ; n=32$ NMJs, from 5 mice) in muscles expressing shRNA $\alpha$ kap compared with NMJs of nonelectroporated (100 $\pm 10 \%$; $n=28$ NMJs, from 4 mice) or scrambled shRNA electroporated muscle cells ( $99 \pm 9 \% ; n=25$ NMJs, for 4 mice). By $7 \mathrm{~d}$ after electroporation, the density of AChRs was significantly decreased at NMJs on muscle fibers expressing GFP-shRNA $\alpha$ kap (60 \pm $12 \% ; n=40 \mathrm{NMJs}$, for 7 mice) compared with nonelectroporated muscle (100 $\pm 16 \% ; n=29$ NMJs, from 5 mice) or muscle electroporated with scrambled shRNA $\alpha$ kap $(101 \pm 15 \%$; $n=24$ NMJs, from 4 mice; $p<0.0001$ electroporated vs nonelectroporated and fibers electroporated with scrambled shRNA). These results indicate that the knockdown of $\alpha$ kap reduces the density of AChRs at postsynaptic sites.

\section{$\alpha$ kap knockdown accelerates the removal rate of receptors, and impairs the insertion of newly synthesized and recycled AChRs into the postsynaptic membrane}

The steady state of the postsynaptic receptor density is established by equilibrium between the rates of removal of receptors from the membrane, and the insertion of newly synthesized and recycled receptors into synaptic sites (Bruneau et al., 2005; Bruneau and Akaaboune, 2006). Having found that shRNA $\alpha$ kap decreased the density of postsynaptic AChRs, we then asked which rates are altered by the knockdown of $\alpha$ kap. To examine this, we first tested whether the insertion of newly synthesized receptors at the synapse was impaired. The sternomastoid muscle was electroporated with GFP-shRNA $\alpha$ kap or its scrambled version. Four days after the electroporation, the sternomastoid muscle was exposed and bathed with a saturating dose of BTX-Alexa Fluor 594 to label AChRs, and superficial synapses were imaged (Fig. 2A). Six days later ( $10 \mathrm{~d}$ after electroporation), the same synapses were reimaged, and the loss of labeled AChRs was measured after the initial labeling. The synapses were bathed again with another saturating dose of BTX-Alexa Fluor 594 to label newly synthesized AChRs that had been inserted after the initial labeling (time $0,4 \mathrm{~d}$ after electroporation; Fig. 2A). The extent of new receptor insertion was estimated as fluorescence recovery after the second dose of fluorescent BTX and expressed as a percentage of the fluorescence at time 0 . We found that the number of newly inserted AChRs at synapses was dramatically depressed in muscle electroporated with shRNA $\alpha$ kap [ $26 \pm 9 \%(n=31$ NMJs, from 6 mice $)$ of original fluorescence; Fig. $2 F, G$, while the insertion of AChRs in nonelectroporated fibers or in muscles electroporated with scrambled version of shRNA $\alpha$ kap was $49 \pm 7 \%(n=28$ NMJs, from 5 mice) and $49 \pm 9 \% \mathrm{SD}$ ( $n=22$ NMJs, 4 mice), respectively, of original fluorescence (Fig. $2 B-E$ ). These results indicate that $\alpha$ kap is involved in the insertion rate of newly synthesized AChRs.

Previous work (Bruneau et al., 2005) showed that recycled AChRs contribute nearly as many receptors as newly synthesized AChRs to the total AChR density at functioning synapses. We therefore assessed whether knocking down $\alpha$ kap also impairs the recycling of AChRs. To test this, sternomastoid muscles electroporated with GFP-shRNA $\alpha$ kap or its scrambled version were bathed with BTX-biotin followed by a saturating dose of streptavidin Alexa Fluor 594, and superficial synapses were imaged as previously described (Bruneau et al., 2005; Bruneau and Akaaboune, 2006). Three days after initial labeling, the sternomastoid muscle was exposed, and the same synapses were imaged again and then bathed with streptavidin Alexa Fluor 594 to selectively label the recycled receptors (receptors that have been internalized, and have lost their streptavidin tag and been reinserted into postsynaptic membrane with their BTX-biotin tag; Bruneau et al., 2005; Martinez-Pena y Valenzuela et al., 2011; Schmidt et al., 2011), and then reimaged. Quantification of fluorescently labeled AChRs showed that in muscles electroporated with GFPshRNA $\alpha$ kap, the total contribution of recycled receptors was $8 \pm$ $3 \%(n=23$ NMJs, from 4 mice $)$ significantly lower than in nonelectroporated ( $23 \pm 6 \% ; n=21 \mathrm{NMJs}, 3$ mice) or scrambled shRNA synapses ( $23 \pm 5 \% ; n=15$ NMJs, from 3 mice) after $3 \mathrm{~d}$ (Fig. $3 B, C$ ). These results indicate that $\alpha$ kap also controls AChR recycling. 
A

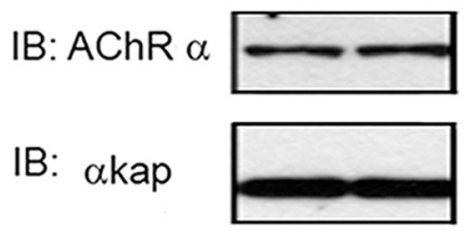

B

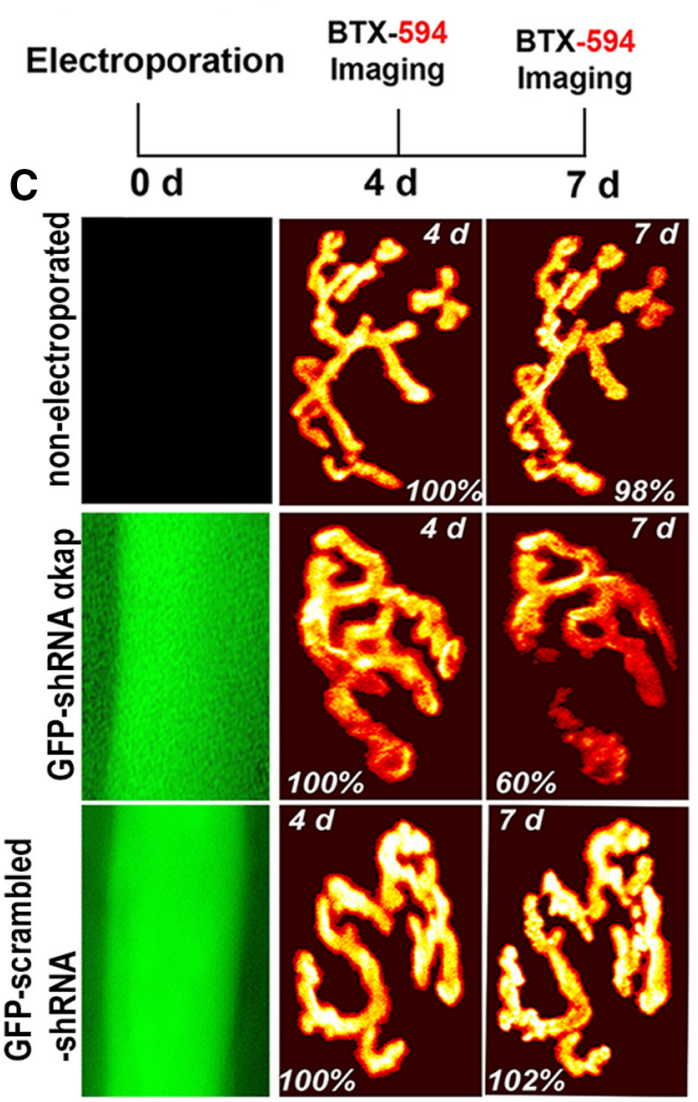

D

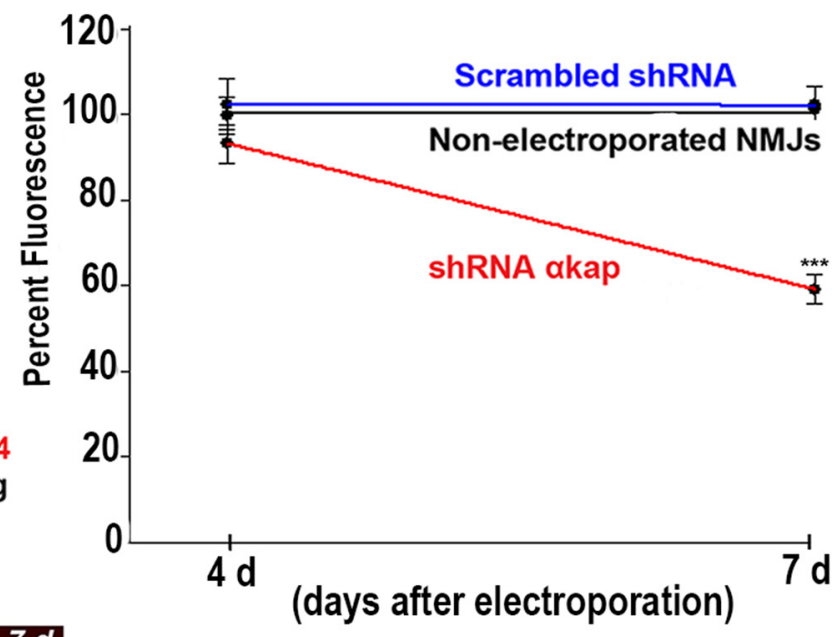

Figure 1. ShRNA $\alpha$ kap significantly reduced the density of postsynaptic AChRs at the NMJ of living mice. $A$, Sternomastoid muscles were lysed, and receptors were labeled with BTX-biotin Labeled AChRs were pulled down with streptavidin beads. Pull-down proteins were then probed with anti- $\alpha$ kap or anti-AChR $\alpha$ antibody. Duplicate experiments are shown. $\boldsymbol{B}$, Experimental protocol. C, Example of NMJs from nonelectroporated or electroporated muscles with shRNA $\alpha$ kap or scrambled shRNA. The sternomastoid muscle of an adult mouse (WT) was electroporated with GFP-shRNA $\alpha$ kap or with a scrambled version of shRNA $\alpha$ kap. At 4 or $7 \mathrm{~d}$ after electroporation, AChRs were labeled with a saturating dose of BTX-Alexa Fluor 594, and superficial synapses on electroporated (green) and nonelectroporated muscle fibers from the same sternomastoid muscle were imaged. Fluorescence intensity of labeled AChRs was measured and normalized to nonelectroporated synapses. $\boldsymbol{D}$, Graph summarizing the mean \pm SD percentage of fluorescence intensity. Note that the density of AChRs was dramatically reduced in shRNA-treated muscles. $* * * p<0.001$

Finally, we tested whether the turnover rate of AChRs (receptors that are already inserted in the membrane) was also affected by the knockdown of $\alpha$ kap. Sternomastoid muscles were electroporated with shRNA $\alpha$ kap, and $7 \mathrm{~d}$ later AChRs were labeled with a subsaturating dose of BTX-Alexa Fluor $594(<20 \%$ of AChRs were labeled, so synapses remain functional; Akaaboune et al., 1999), and synapses were imaged and reimaged $3 \mathrm{~d}$ later to assess changes in fluorescence intensity. In muscles treated with shRNA $\alpha \mathrm{kap}, \sim 50 \%$ of the fluorescently tagged AChRs were lost from synaptic sites, corresponding to a $t_{1 / 2}$ of $\sim 3 \mathrm{~d}(3 \pm 1.4 \% ; n=23$ NMJs, from 4 mice); whereas, in nonelectroporated neighboring fibers, the loss of fluorescently labeled receptors was only $20 \%$, corresponding to a $t_{1 / 2}$ of $\sim 9 \mathrm{~d}(9.2 \pm 1.7 \% ; n=18 \mathrm{NMJs}$, from
3 mice), and in muscles treated with scrambled shRNA $20 \%$ of AChRs were lost $\left(t_{1 / 2}, \sim 9 \mathrm{~d} ; 9.1 \pm 1.1 \% ; n=14\right.$ NMJs, from 3 mice; Fig. $4 B, C)$. These results indicate that $\alpha$ kap also controls the removal rate of AChRs from synaptic sites.

Since rapsyn binds directly to AChRs, we sought to determine whether $\alpha$ kap also controls the turnover rate of rapsyn at the synapse. Adult mice were electroporated with either rapsyn-GFP alone, or rapsyn-GFP and shRNA $\alpha$ kap. Seven days after electroporation, sternomastoid muscles were exposed and synapses expressing rapsyn-GFP were imaged. Discrete portions of individual junctions were carefully traced with an argon laser to remove the fluorescence without altering fluorescence intensity at other regions of the NMJ and then reimaged. Twenty-four hours 
A

\begin{tabular}{|c|c|c|c|}
\hline Electroporation & $\begin{array}{c}\text { BTX-594 } \\
\text { Imaging } \\
\text { (1st view) }\end{array}$ & $\begin{array}{c}\text { Imaging } \\
\text { (2nd view) }\end{array}$ & $\begin{array}{l}\text { Imaging } \\
\text { (3rd view) }\end{array}$ \\
\hline$-4 d$ & $0 \mathrm{~d}$ & $+6 d^{\Lambda}$ & BTX-Alexas \\
\hline
\end{tabular}

B

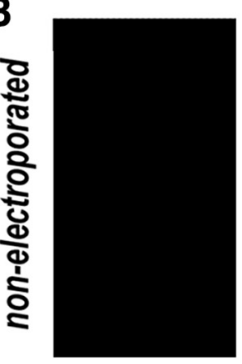

D

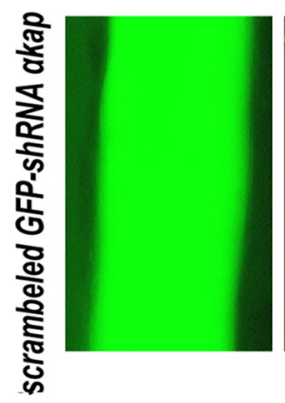

$\mathbf{F}$
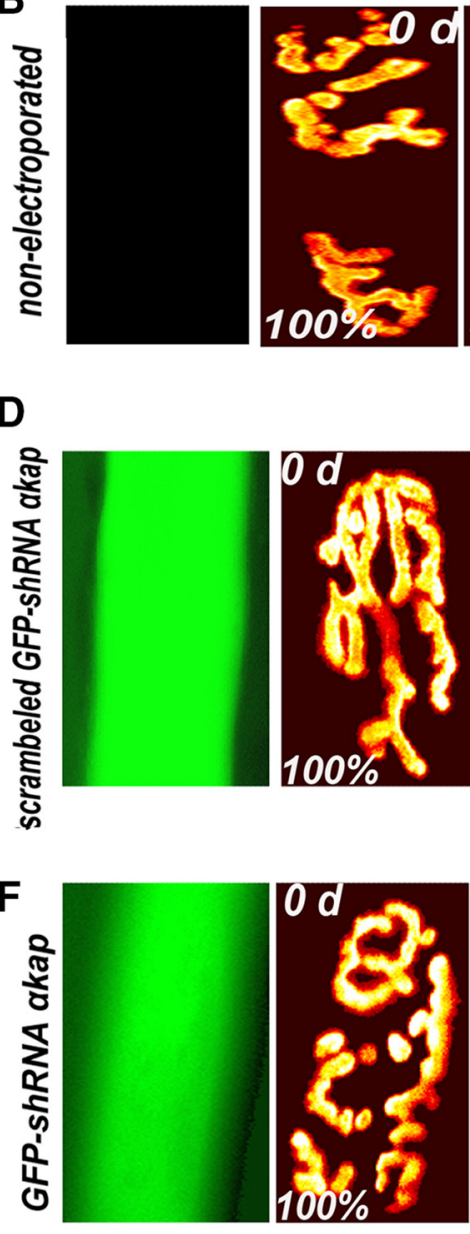

od
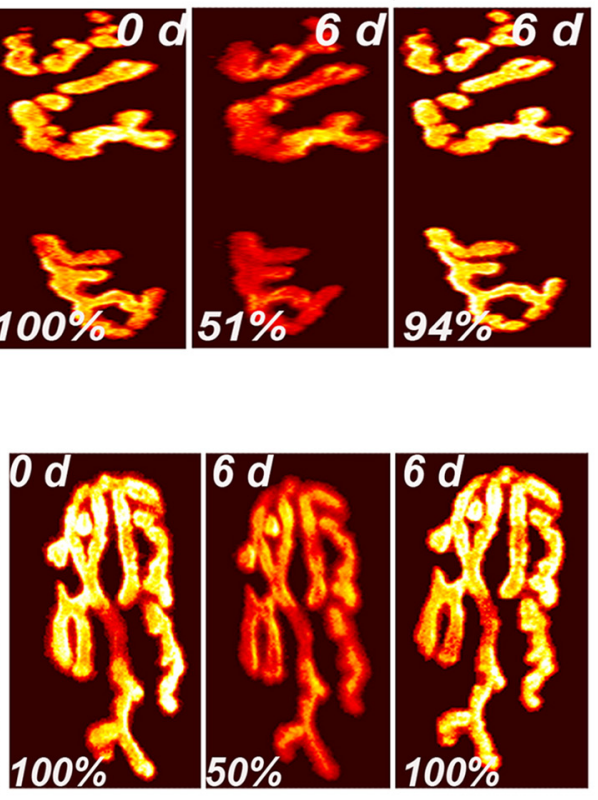

E
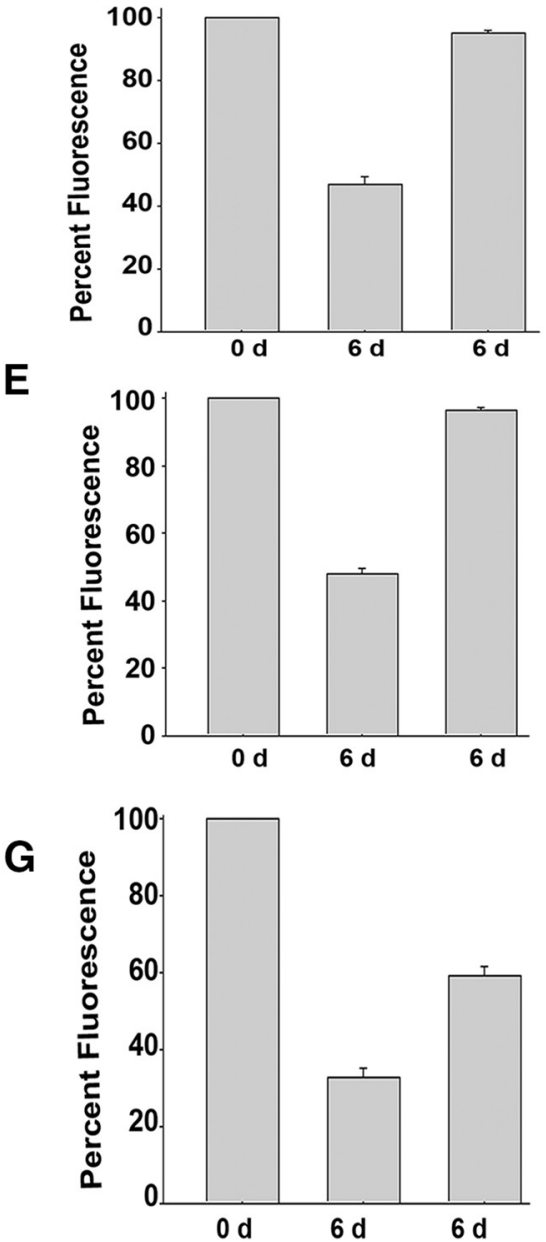

Figure 2. ShRNA $\alpha$ kap impaired the insertion rate of newly synthesized AChRs. A, Labeling protocol for assessing the amount of receptor insertion. Four days after electroporation of sternomastoid muscles with shRNA- $\alpha$ kap or scrambled shRNA $\alpha$ kap, AChRs were saturated with BTX-Alexa Fluor 594, and NMJs were imaged. Six days after the initial imaging, the same NMJs were reimaged to measure the loss of fluorescence and then relabeled with a saturating dose of BTX-Alexa Fluor 594 to measure the number of new receptors that had been inserted after the initial labeling. $\boldsymbol{B}$, Example of three views of the same image from nonelectroporated muscle. All three panels of images are displayed on the same intensity scale. $\boldsymbol{D}$, Example of three views of the same NMJ in mice electroporated with scrambled shRNA. $\boldsymbol{F}$, Example of three views of NMJs treated with GFP-shRNA $\alpha$ kap. $\boldsymbol{C}, \boldsymbol{E}, \boldsymbol{G}$, Bar graphs summarizing the mean \pm SE percentage of fluorescence intensity. Note that very little fluorescence was gained after BTX-Alexa Fluor 594 was added (26\% of the original fluorescence), indicating that the insertion of AChR was significantly depressed in muscles electroporated with shRNA.

later, the same synapses were imaged, and the recovery of fluorescence at the bleached portion of each junction was measured and normalized to the amount of rapsyn-GFP expression at unbleached regions of the same junction as described by Bruneau et al. (2010) and Bruneau and Akaaboune (2010). Quantification of fluorescence recovery from synapses expressing rapsyn-GFP was $50 \pm 8 \%(\mathrm{NMJs}=7$, from 3 mice $)$ of fluorescence at bleached regions of synapses (which corresponds to a $t_{1 / 2}$ of $\sim 24 \mathrm{~h}$ ) and $26 \pm 8 \%(\mathrm{NMJs}=9$, from 3 mice) of fluorescence at the bleached synapses expressing both rapsyn and shRNA $\alpha$ kap $\left(t_{1 / 2}, \sim 10 \mathrm{~h}\right)$. This result suggests that the insertion of rapsyn was impaired by shRNA $\alpha$ kap.

The knockdown of endogenous $\alpha$ kap impairs the structure of the neuromuscular junction

To examine whether shRNA $\alpha$ kap expression has any effect on synaptic structure, the sternomastoid muscle electroporated with GFP-shRNA $\alpha$ kap or scrambled GFP-shRNA $\alpha$ kap (7 d after 


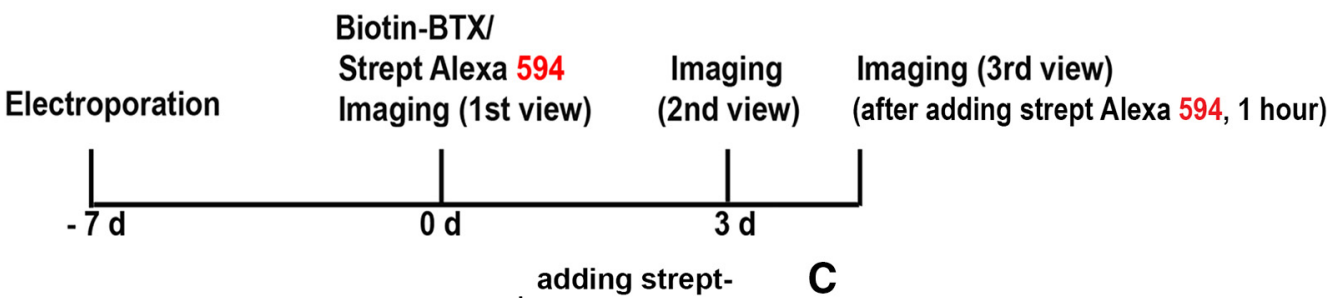

B
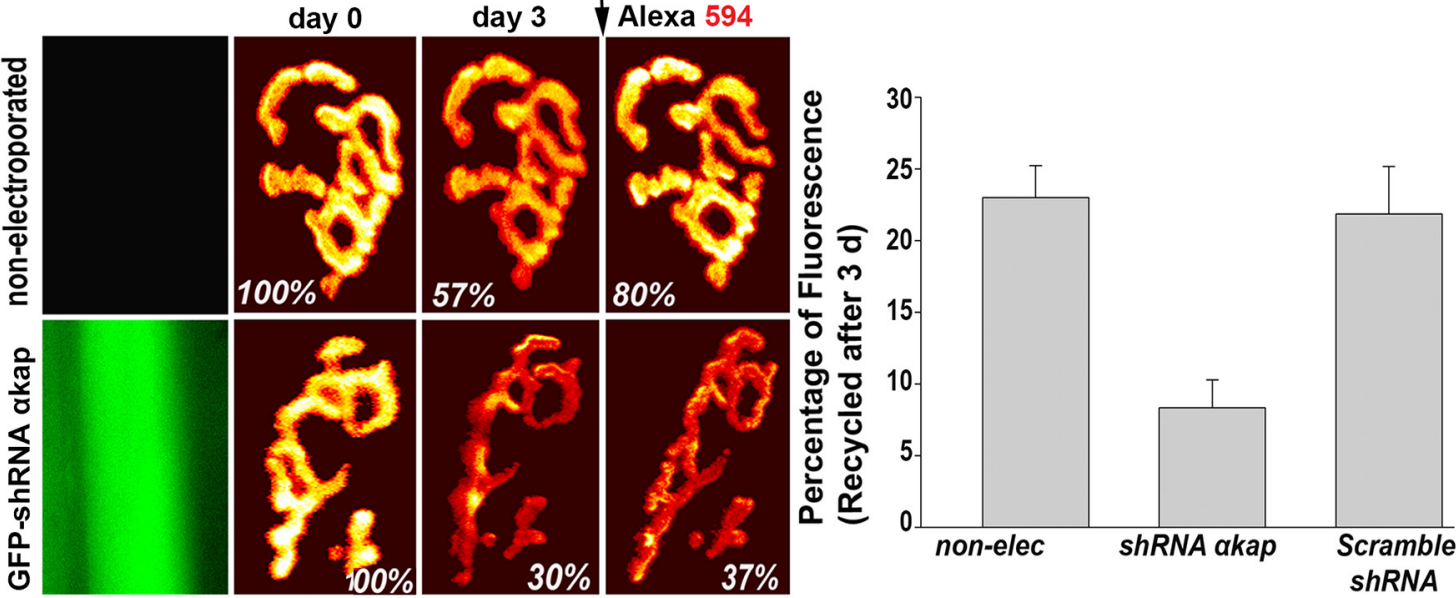

Figure 3. shRNA $\alpha$ kap decreased the contribution of recycled AChRs to the synapse. $\boldsymbol{A}$, Scheme of the protocol used to label recycled AChRs. Seven days after electroporation, muscles were labeled with a saturating dose of BTX-biotin followed by streptavidin Alexa Fluor 594, and NMJs were imaged. Three days later, the same synapses were imaged for the second time, and then receptors were labeled with Streptavidin Alexa Fluor 594 and reimaged again. $\boldsymbol{B}$, Examples of three views of a nonelectroporated synapse and an shRNA $\alpha$ kap electroporated synapse following the recycling labeling protocol described in A. C, Graph summarizing the contribution of receptor recycling to the density of an AChR. Note that the recycling of AChRs was significantly decreased in muscles treated with shRNA $\alpha$ kap.

electroporation) was labeled with BTX-Alexa Fluor 594, fixed, and then scanned with confocal microscopy. High-resolution images revealed that virtually all neuromuscular synapses on fibers expressing GFP in shRNA $\alpha$ kap-treated fibers exhibited areas devoid of receptors (holes), giving the receptor cluster a perforated appearance compared with scrambled shRNA and nonelectroporated synapses (Fig. 5A-G). Quantification of holes (size, $\geq 5 \mu \mathrm{m}$ ) showed that 113 of 150 NMJs had $>4$ perforations (between 4 and 11 holes). In contrast, nonelectroporated synapses ( 80 of 90 NMJs) or synapses treated with scrambled shRNA (56 of 60 NMJs) had more than one hole (11\%), while a vast majority of synapses had no holes (89\%; Fig. 5G,H). Next, we examined whether AChR holes developed from focal receptor loss from the synaptic cluster. Electroporated muscles treated with shRNA $\alpha$ kap were doubly labeled with $\alpha$-BTX-Alexa Fluor 594 (red) to label AChRs and VVA B4 lectin (green), a marker that labels $N$-acetyl-D-galactosamine $\beta$-terminal saccharide moieties present specifically at the neuromuscular junction (including the asymmetric form of acetylcholinesterase (AChE; Scott et al., 1988), which shows the original location of the synapses. More than 50\% of holes from which AChR fluorescence was missing exhibited VVA B4 lectin staining (Fig. $5 I-L)$. We also found that $\sim 50 \%$ of synapses exhibit holes that are missing both receptors and VVA B4 staining, suggesting that both receptors and AChEs or other glycoproteins at the synaptic cleft are removed.

Previous studies (Adams et al., 2000; Grady et al., 2000; Sanes and Lichtman, 2001; Wu et al., 2010; Pires-Oliveira et al., 2013) have shown that the tethering of AChRs to the postsynaptic membrane is controlled by scaffold proteins. We asked whether the knockdown of $\alpha$ kap is also involved in the loss of AChRassociated proteins from sites where AChRs had disappeared.
Muscles electroporated with shRNA $\alpha$ kap and rapsyn-GFP, $\alpha$-syntrophin-GFP, or $\alpha$-dystrobrevin-GFP (7 d after electroporation) were labeled with BTX-Alexa Fluor 594, and NMJs were scanned with the confocal microscope. Analyses of highresolution images of synapses electroporated with shRNA $\alpha$ kap and rapsyn showed that in the endplates that had lost synaptic sites $(\mathrm{NMJ}=18$, from 5 mice), both receptor and rapsyn are no longer visible (Fig. 6A-C). This indicates that rapsyn and AChRs are lost from synaptic sites simultaneously at the same rate. In synapses electroporated with $\alpha$-syntrophin $(\mathrm{NMJ}=$ 16 , from 4 mice) or $\alpha$-dystrobrevin ( $\mathrm{NMJ}=16$, from 3 mice), $\sim 70 \%$ of lost receptor clusters showed the presence of these proteins, indicating that $\alpha$-syntrophin $/ \alpha$-dystrobrevin and AChRs disappear sequentially from the synapse (Fig. $6 D-I$ ). Altogether, these results suggest that the knockdown of $\alpha \mathrm{kap}$ affects not only receptor stability but also induces the disassembly of their anchoring postsynaptic proteins from the entire synaptic site (see Discussion).

Previous studies showed that the CaMKII $\beta \mathrm{m}$ isoform is highly expressed at the NMJ and plays an important role in the recycling of AChR into synaptic sites (Martinez-Pena y Valenzuela et al., 2010). It was also reported that $\alpha$ kap plays a role in targeting multiple calcium/calmodulin kinase II isoforms to their specific subcellular locations, where they can act (Nori et al., 2003). Here we sought to determine whether $\alpha$ kap is accumulated at the NMJ and whether the localization of CaMKII $\beta \mathrm{m}$ is affected by $\alpha$ kap depletion from muscle cells. Sternomastoid muscles were electroporated with GFP- $\alpha$ kap, GFP-CaMKII $\beta \mathrm{M}$, or both GFP-CaMKII $\beta$ M and shRNA $\alpha$ kap, and $7 \mathrm{~d}$ later muscles were fixed and imaged with the confocal microscope. In muscles electroporated with GFP- $\alpha$ kap, we found no accumulation of $\alpha$ kap at the NMJ (data not shown), and, as expected, GFP- 
CaMKII $\beta M$ is strongly expressed at the NMJ (data not shown). However, the localization of GFP-CaMKII $\beta$ M at NMJs is not affected by shRNA $\alpha$ kap, indicating that $\alpha$ kap is not necessary for the targeting and localization of GFP-CaMKII $\beta M$ at the NMJ (Fig. 6K). Like other associated scaffold proteins, in electroporated muscle cells (NMJ $=12$, from 3 mice) $\sim 80 \%$ of lost receptor clusters showed the presence of GFP-CaMKII $\beta$ M (Fig. $6 J-L$ ). This indicates that $\mathrm{CaMKII} \beta \mathrm{M}$ also disappears at a slower rate than AChRs.

Finally, we examined whether the disassembly of the postsynaptic apparatus observed in muscles treated with shRNA $\alpha$ kap is also accompanied by the retraction of the overlying nerve terminal. Seven days after electroporation, muscles were immunostained with antibodies against neurofilaments, and SV2 and synapses were imaged with the confocal microscope. As shown in Figure $6 M-O$, we found that synaptic clusters that had lost AChRs were still covered by presynaptic terminal branches $(\mathrm{NMJs}=19$, from 5 mice). However, 3 weeks after the electroporation of muscles with shRNA $\alpha$ kap, the withdrawal of the nerve terminal was seen from faintly stained and disorganized receptor regions $(\mathrm{NMJ}=18$, from 3 mice; Fig. $6 P-R)$. Altogether, these results indicate that the withdrawal of the presynaptic nerve terminal in treated muscles with shRNA $\alpha$ kap is a slow process and is initiated by a decrease or loss of the density of postsynaptic AChRs.

\section{Discussion}

This work demonstrates that the knockdown of the endogenous expression of $\alpha$ kap in muscle cells of living mice destabilizes the molecular dynamics of AChRs and the structural integrity of the neuromuscular synapses. These conclusions are supported by the following findings: (1) $\alpha$ kap and AChRs are present in the same complex; (2) knockdown of $\alpha$ kap induces a significant reduction in the overall postsynaptic density of AChR; (3) knockdown of $\alpha$ kap accelerates AChR turnover and depresses the insertion rates of newly synthesized and recycled AChRs into synaptic sites; (4) some receptor clusters disappear from the postsynaptic site in muscle treated with shRNA $\alpha$ kap, but not with its scrambled version; (5) there is complete dissipation of the associated scaffold protein rapsyn from areas devoid of AChRs; (6) there is reduction or complete disassembly of several markers of the postsynaptic apparatus; and (7) the overlying nerve terminal withdraws from eliminated synaptic sites.
A

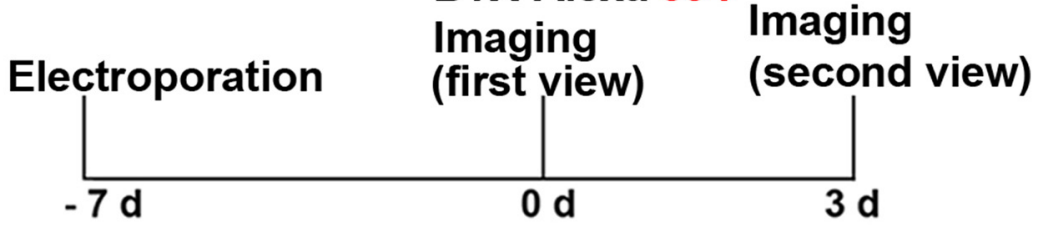

B
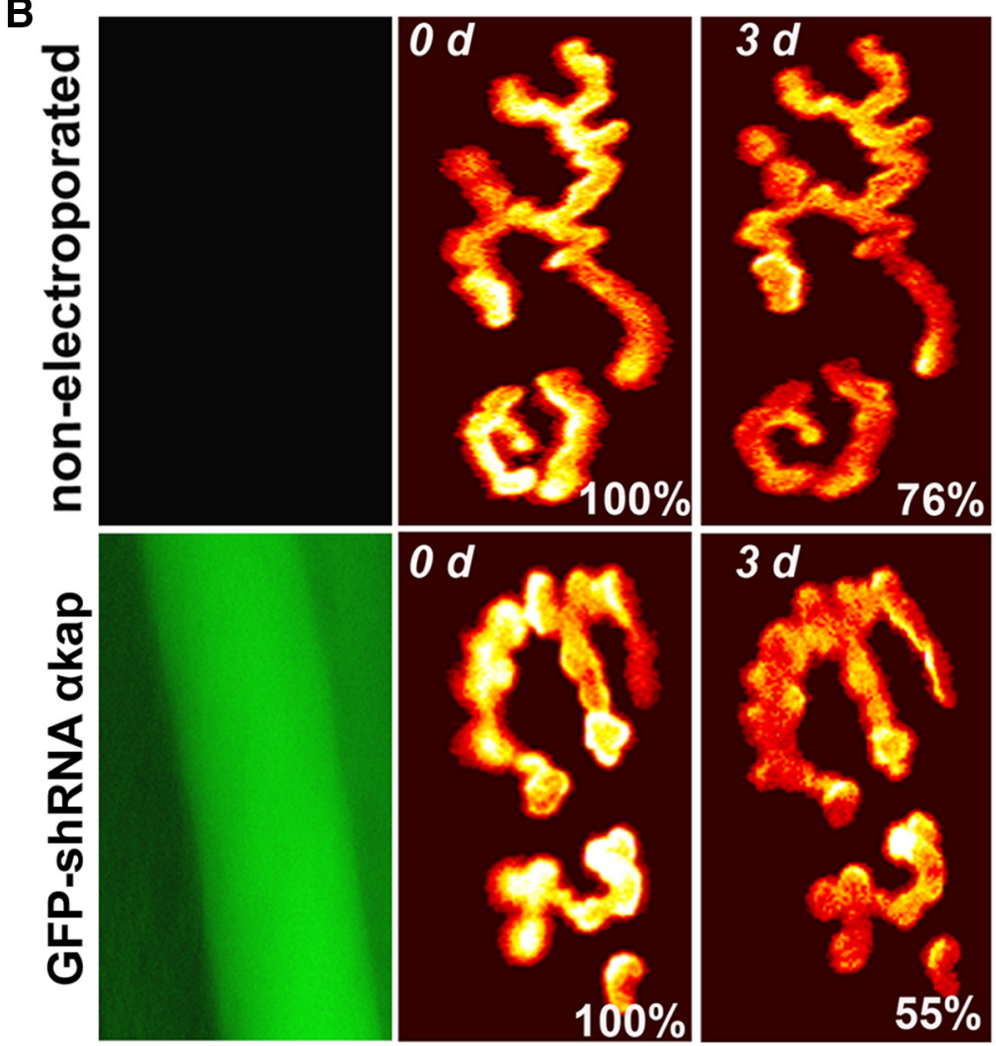

C

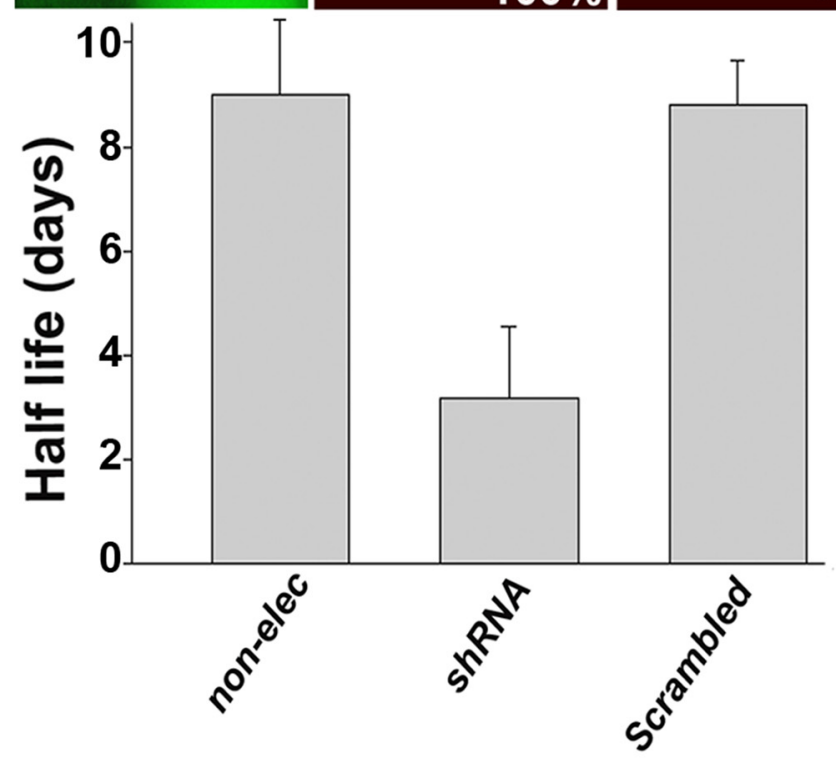

Figure 4. shRNA $\alpha$ kap enhanced the turnover rate of AChR at the postsynaptic membrane. $A$, Experimental protocol. The sternomastoid muscle of mice treated with shRNA $\alpha$ kap or scrambled shRNA were labeled with a nonsaturating dose of BTX-Alexa Fluor 594 ( $7 \mathrm{~d}$ after electroporation), and superficial synapses were imaged at time 0 and reimaged $3 \mathrm{~d}$ later. The total fluorescence intensity of a labeled AChR was normalized to $100 \%$ at initial imaging. $\boldsymbol{B}$, Examples of two views of the same NMJs imaged from muscles electroporated with shRNA and nonelectroporated neighboring muscle fibers. $\boldsymbol{C}$, Graph summarizing the half-life (days) of AChRs in NMJs treated with shRNA, nonelectroporated neighboring NMJs, or shRNA scrambled NMJs. Note that the turnover rate of AChRs is significantly higher in shRNA $\alpha$ kap synapses compared with nonelectroporated and scrambled synapses. 

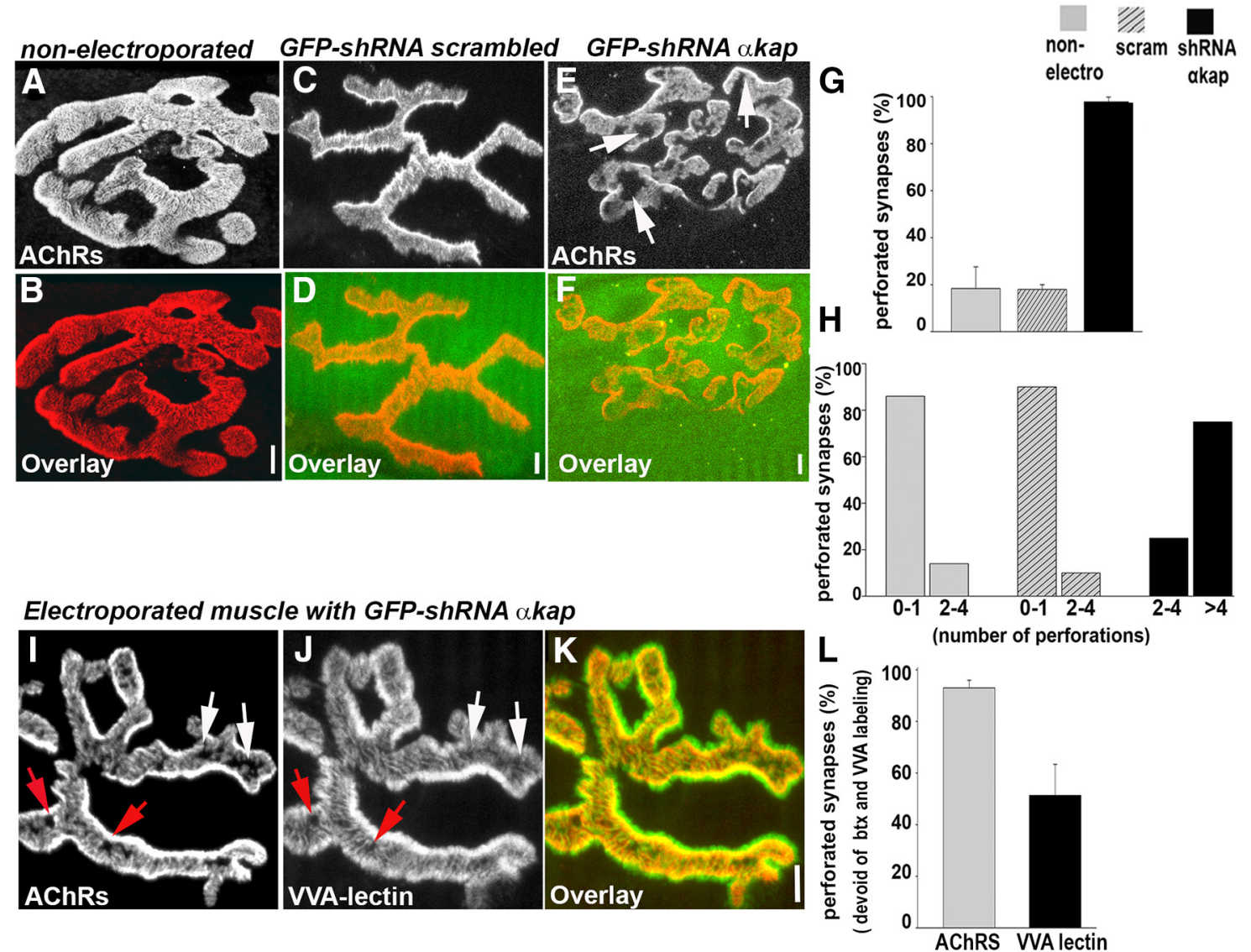

Figure 5. Disappearance of receptors from synaptic clusters in mice treated with shRNA $\alpha$ kap. The sternomastoid muscle was electroporated with GFP-shRNA $\alpha$ kap or scrambled GFP-shRNA $\alpha$ kap. At $7 \mathrm{~d}$, muscles were labeled with BTX-Alexa Fluor 594, fixed, and imaged with a confocal microscope. $A$, $B$, Example of a confocal image of an NMJ in nonelectroporated muscle. $\boldsymbol{C}, \boldsymbol{D}$, Example of an NMJ confocal image of a muscle electroporated with scrambled shRNA $\alpha$ kap. $\boldsymbol{E}, \boldsymbol{F}$, Example of an NMJ confocal image of a muscle electroporated with shRNA $\alpha$ kap. Arrows indicate numerous perforations (holes) found in muscles treated with shRNA $\alpha$ kap. $\mathbf{G}$, Graph showing the percentage of synapses with perforated clusters. $\boldsymbol{H}$, Graph showing the number of perforations per NMJ in muscles electroporated with either shRNA $\alpha$ kap or scrambled and nonelectroporated muscles. $I, J$, High-resolution images of NMJs double labeled with $\alpha$-BTX-Alexa Fluor 594 (AChRs, red) and VVA B4 lectin-Alexa Fluor 488 (green). $\boldsymbol{K}$, Overlay of green and red. Note that in several synaptic clusters where receptors are missing, VVA lectin staining is still present (see white arrows), indicating that perforations form in cluster regions previously occupied by AChRs. Red arrows indicate that both AChR and VVA are missing from synaptic clusters. $L$, Graph showing the percentage of shRNA $\alpha$ kap-electroporated synapses with perforated clusters lacking $\alpha$-BTX-Alexa Fluor 594 and VVA B4 lectin labeling. Note that almost $100 \%$ of NMJs are perforated after $7 \mathrm{~d}$ (the perforations are no longer labeled by $\alpha$-BTX-Alexa Fluor 594 ) and that in $50 \%$ of those synapses VVA B4 lectin is still present. Scale bars, $5 \mu \mathrm{m}$.

Consistent with these results, in cultured myotubes $\alpha$ kap was found to interact with AChRs, and when cells were treated with shRNA, few receptors were expressed and clustered on the surface of muscle cells while the amount of AChR $\alpha$ mRNA remained unaffected (Mouslim et al., 2012). The current results show that in muscles treated with $\alpha$ kap shRNA, both the rate of insertion of newly synthesized and of the reinsertion of recycled receptors, and the rate of removal of AChRs were altered. This suggests that $\alpha$ kap acts simultaneously on the following three different pathways of receptor trafficking: the insertion of newly synthesized AChRs from the endoplasmic reticulum (ER) to the cell surface; the recycling of internalized AChRs into postsynaptic membrane; and the removal/internalization of receptors from the postsynaptic membrane. Previous studies from our laboratory and others have shown that $\alpha$ kap localizes to the ER in skeletal and cardiac muscles (Nori et al., 2003; Singh et al., 2009) and in heterologous HEK cells (Mouslim et al., 2012), and is also found to be diffused throughout the muscle fibers, without being concentrated with receptors at the synapse. Thus, it is possible that lack of $\alpha \mathrm{kap}$ may promote the degradation of synthesized AChRs during their sojourn in the secretory pathway, leading to fewer receptors at synaptic sites. Consistent with this idea, we previously showed that in myotubes transfected with shRNA $\alpha$ kap and treated with proteasome inhibitors the degradation of receptors was largely prevented. Similarly, in HEK cells overexpressed with AChR $\alpha$ and treated with either $\alpha$ kap or proteasome inhibitors, the stability of the $\mathrm{AChR} \alpha$ subunit was significantly increased compared with the stability of $\operatorname{AChR} \alpha$ without $\alpha$ kap or proteasome inhibitors (Mouslim et al., 2012). Also when the same cells were overexpressed with a construct containing mutations of $\mathrm{AChR} \alpha$ lysine residues that are required for ubiquitination, the degradation of $\operatorname{AChR} \alpha$ was largely prevented (Mouslim et al., 2012).

Recent studies have shown that $\alpha$ kap also controls the stability of Lrp4, a transmembrane protein that transmits a signal required for the clustering of AChRs, in heterologous HEK cells. Similar to AChR, it is possible that $\alpha$ kap may also protect Lrp4 from degradation by the proteasome. Thus, it is conceivable that the stabilization of Lrp 4 in the postsynaptic membrane by $\alpha$ kap is critical for the binding of agrin and the activation of the intracellular pathway downstream of MuSK, which ultimately lead to the clustering of receptors (Wu et al., 2010). The fact that the vast majority of $\alpha$ kap is diffusely distributed throughout the cytoplasm and is associated with sarcomeres of skeletal muscles 

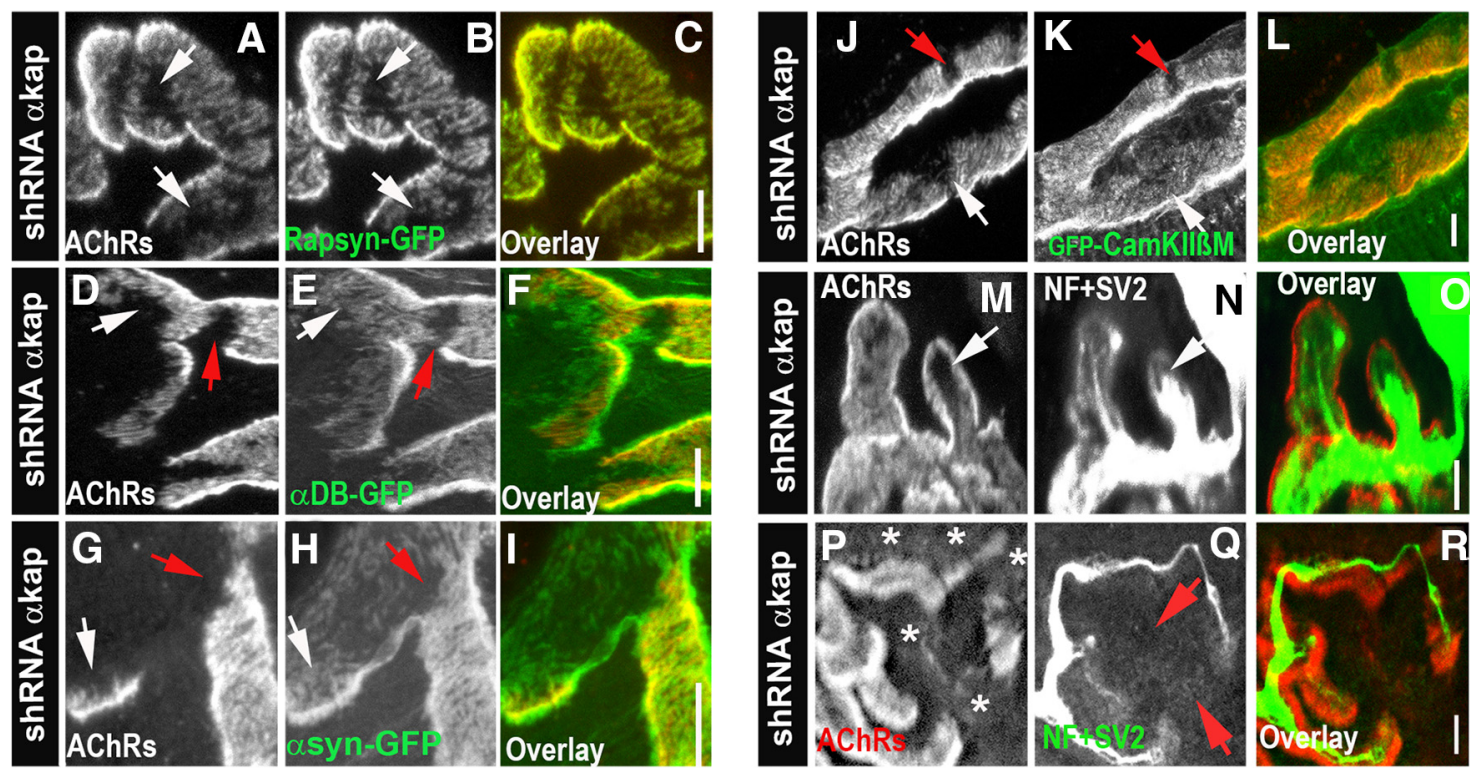

Figure 6. Neuromuscular junction disassembly in muscles treated with shRNA $\alpha$ kap. The sternomastoid muscle was electroporated with shRNA $\alpha$ kap and rapsyn-GFP, $\alpha$-syntrophinGFP, $\alpha$-dystrobrevin GFP, or GFP-CaMKII $\beta$ M; and $7 \mathrm{~d}$ after electroporation, muscles were labeled with BTX-Alexa Fluor 594 and fixed, and then synapses were imaged. $\boldsymbol{A}$ - $\boldsymbol{C}$, Example of a high-resolution confocal image of a NMJ expressing rapsyn-GFP and labeled with BTX-Alexa Fluor 594. Note that rapsyn-GFP colocalized perfectly with receptors at synaptic sites, except in regions where receptors have been lost (see arrows), indicating that rapsyn and AChRs are removed simultaneously. $D-L$, Examples of a high-resolution confocal image of a NMJ expressing $\alpha$-dystrobrevin-GFP ( $\alpha$ DB-GFP; $\boldsymbol{D}-\boldsymbol{F}), \alpha$-syntrophin-GFP $(\boldsymbol{G}-\boldsymbol{I})$, and GFP-CaMKII $\beta \mathrm{M}(\boldsymbol{J}-\boldsymbol{L})$. Note that $\alpha$-syntrophin, $\alpha$-dystrobrevin, and $\mathbf{C a M K I I} \beta M$ are no longer present at some perforated synaptic clusters (red arrows), but not in others (white arrows), suggesting that AChRs and these molecules have different rates of removal. $\boldsymbol{M}-\boldsymbol{R}$, Seven days ( $\boldsymbol{M}-\mathbf{0}$ ) and $21 \mathrm{~d}(\boldsymbol{P}-\boldsymbol{R})$ after electroporation with shRNA $\alpha$ kap, muscles were fixed and stained with antibodies against Sv2/neurofilament (green) and BTX-Alexa Fluor 594 . Note that synaptic nerve terminal branches remain visible at synaptic sites where receptors are lost at $7 \mathrm{~d}$ (white arrows), but they are removed by $21 \mathrm{~d}$ (red arrows); asterisks show areas of synaptic clusters where receptors are faint or completely missing. Scale bars, $5 \mu \mathrm{m}$.

(Bayer et al., 1996, 1998) might also suggest that $\alpha$ kap acts as a chaperone molecule that controls the ubiquitination of AChRs in the postsynaptic membrane and/or scaffold-associated proteins that are involved in the tethering of AChRs. Similar to this, it has been shown that an HSP90 $\beta$, a cytoplasmic molecular chaperon (Luo et al., 2008), controls the stability and the turnover of rapsyn in a proteasome-dependent mechanism, and consequently the clustering of AChR. Along these lines, several studies (Ehlers, 2003; Speese et al., 2003; Mabb and Ehlers, 2010) have shown that the ubiquitin-proteasome system is involved in regulating synaptic protein turnover and synaptic efficacy at a variety of synapses.

The present experiments show that the knockdown of $\alpha$ kap expression had a profound effect on the structural integrity of the NMJ. Several postsynaptic proteins were removed either simultaneously or sequentially with receptors at clusters devoid of AChRs in muscles treated with shRNA $\alpha$ kap. Thus, it is possible that the depletion of $\alpha$ kap may enhance directly or indirectly the degradation of these proteins during their intracellular trafficking to postsynaptic sites or their removal from synaptic membranes. However, our previous studies showed that in cultured myotubes treated with shRNA directed against $\alpha$ kap, no changes in rapsyn protein level were observed compared with the dramatic decrease in AChR $\alpha$ level. Similarly, $\alpha$ kap did not show any effect on the stability of $\alpha$-syntrophin and $\alpha$-dystrobrevin when they were coexpressed with $\alpha$ kap in HEK cells. Of note, in our previous study (Mouslim et al., 2012) we did not examine the disassembly of these postsynaptic proteins from receptor clusters in $\alpha$ kap-depleted myotubes. It is possible that the local disassembly of the postsynaptic apparatus scaffold proteins from synaptic clusters in vivo, where receptors are missing, is not a direct consequence of $\alpha$ kap knockdown. Rather, it may be triggered by the dissipation of postsynaptic AChRs, as they are tightly controlled by $\alpha$ kap in both cultured myotubes and heterologous HEK cells (Mouslim et al., 2012).

The current work raises the question how the knockdown of $\alpha$ kap could induce the focal disappearance of AChRs and the postsynaptic apparatus from the synaptic membrane. The uneven distribution of AChRs over the entire synapse and defects in receptor trafficking (rapid turnover rate of receptors from the postsynaptic membrane, and low insertion rates of newly synthesized and recycled AChR) induced by $\alpha$ kap depletion all would contribute to lowering AChR density below critical levels that are essential for their local maintenance and consequently a complete dissipation of receptor clusters. AChRs have been shown to be essential for the local maintenance and accumulation of intracellular scaffolding proteins (Missias et al., 1997; Marangi et al., 2001; Ono et al., 2001, 2004; Mouslim et al., 2012). For instance, the dissipation of AChRs from clusters in cultured myotubes (induced by focal laser illumination) triggered the disappearance of associated scaffold proteins, including rapsyn (Bruneau et al., 2008), and in zebrafish deficient in AChRs, rapsyn failed to form clusters (Ono et al., 2001, 2004). Thus, it is possible that the disappearance of postsynaptic scaffold proteins such as rapsyn, $\alpha$-syntrophin, $\alpha$-dystrobrevin, CaMKII $\beta \mathrm{M}$, and others is initiated by receptor removal.

Overall, the results presented here provide new insights about the role of a muscle-specific nonkinase anchoring protein ( $\alpha \mathrm{kap})$ in regulating the trafficking of AChRs, the stability of AChR density, and the maintenance of the structural integrity of the synapse, which are required for the effectiveness of synaptic impulses between nerve and muscle cells. 


\section{References}

Adams ME, Kramarcy N, Krall SP, Rossi SG, Rotundo RL, Sealock R, Froehner SC (2000) Absence of alpha-syntrophin leads to structurally aberrant neuromuscular synapses deficient in utrophin. J Cell Biol 150:1385-1398. CrossRef Medline

Akaaboune M, Culican SM, Turney SG, Lichtman JW (1999) Rapid and reversible effects of activity on acetylcholine receptor density at the neuromuscular junction in vivo. Science 286:503-507. CrossRef Medline

Bayer KU, Löhler J, Harbers K (1996) An alternative, nonkinase product of the brain-specifically expressed Ca2+/calmodulin-dependent kinase II alpha isoform gene in skeletal muscle. Mol Cell Biol 16:29-36. Medline

Bayer KU, Harbers K, Schulman H (1998) alphaKAP is an anchoring protein for a novel CaM kinase II isoform in skeletal muscle. EMBO J 17: 5598-5605. CrossRef Medline

Bayer KU, De Koninck P, Schulman H (2002) Alternative splicing modulates the frequency-dependent response of CaMKII to $\mathrm{Ca}(2+)$ oscillations. EMBO J 21:3590-3597. CrossRef Medline

Bruneau EG, Akaaboune M (2006) The dynamics of recycled acetylcholine receptors at the neuromuscular junction in vivo. Development 133:44854493. CrossRef Medline

Bruneau EG, Akaaboune M (2010) Dynamics of the rapsyn scaffolding protein at the neuromuscular junction of live mice. J Neurosci 30:614-619. CrossRef Medline

Bruneau EG, Brenner DS, Kuwada JY, Akaaboune M (2008) Acetylcholine receptor clustering is required for the accumulation and maintenance of scaffolding proteins. Curr Biol 18:109-115. CrossRef Medline

Bruneau E, Sutter D, Hume RI, Akaaboune M (2005) Identification of nicotinic acetylcholine receptor recycling and its role in maintaining receptor density at the neuromuscular junction in vivo. J Neurosci 25:9949-9959. CrossRef Medline

Campbell KP, MacLennan DH (1982) A calmodulin-dependent protein kinase system from skeletal muscle sarcoplasmic reticulum. Phosphorylation of a 60,000-dalton protein. J Biol Chem 257:1238-1246. Medline

Damiani E, Picello E, Saggin L, Margreth A (1995) Identification of triadin and of histidine-rich $\mathrm{Ca}(2+)$-binding protein as substrates of $60 \mathrm{kDa}$ calmodulin-dependent protein kinase in junctional terminal cisternae of sarcoplasmic reticulum of rabbit fast muscle. Biochem Biophys Res Commun 209:457-465. CrossRef Medline

Ehlers MD (2003) Activity level controls postsynaptic composition and signaling via the ubiquitin-proteasome system. Nat Neurosci 6:231-242. CrossRef Medline

Fluck M, Booth FW, Waxham MN (2000) Skeletal muscle CaMKII enriches in nuclei and phosphorylates myogenic factor SRF at multiple sites. Biochem Biophys Res Commun 270:488-494. CrossRef Medline

Gautam M, Noakes PG, Mudd J, Nichol M, Chu GC, Sanes JR, Merlie JP (1995) Failure of postsynaptic specialization to develop at neuromuscular junctions of rapsyn-deficient mice. Nature 377:232-236. CrossRef Medline

Glass DJ, DeChiara TM, Stitt TN, DiStefano PS, Valenzuela DM, Yancopoulos GD (1996) The receptor tyrosine kinase MuSK is required for neuromuscular junction formation and is a functional receptor for agrin. Cold Spring Harb Symp Quant Biol 61:435-444. CrossRef Medline

Grady RM, Grange RW, Lau KS, Maimone MM, Nichol MC, Stull JT, Sanes JR (1999) Role for alpha-dystrobrevin in the pathogenesis of dystrophin-dependent muscular dystrophies. Nat Cell Biol 1:215-220. CrossRef Medline

Grady RM, Zhou H, Cunningham JM, Henry MD, Campbell KP, Sanes JR (2000) Maturation and maintenance of the neuromuscular synapse: genetic evidence for roles of the dystrophin-glycoprotein complex. Neuron 25:279-293. CrossRef Medline

Kim N, Stiegler AL, Cameron TO, Hallock PT, Gomez AM, Huang JH, Hubbard SR, Dustin ML, Burden SJ (2008) Lrp4 is a receptor for agrin and forms a complex with MuSK. Cell 135:334-342. CrossRef Medline

Luo S, Zhang B, Dong XP, Tao Y, Ting A, Zhou Z, Meixiong J, Luo J, Chiu FC, Xiong WC, Mei L (2008) HSP90 beta regulates rapsyn turnover and subsequent AChR cluster formation and maintenance. Neuron 60:97110. CrossRef Medline

Mabb AM, Ehlers MD (2010) Ubiquitination in postsynaptic function and plasticity. Annu Rev Cell Dev Biol 26:179-210. CrossRef Medline

Marangi PA, Forsayeth JR, Mittaud P, Erb-Vögtli S, Blake DJ, Moransard M,
Sander A, Fuhrer C (2001) Acetylcholine receptors are required for agrin-induced clustering of postsynaptic proteins. EMBO J 20:7060 7073. CrossRef Medline

Martinez-Pena y Valenzuela I, Mouslim C, Akaaboune M (2010) Calcium/ calmodulin kinase II-dependent acetylcholine receptor cycling at the mammalian neuromuscular junction in vivo. J Neurosci 30:12455-12465. CrossRef Medline

Martinez-Pena y Valenzuela I, Mouslim C, Pires-Oliveira M, Adams ME, Froehner SC, Akaaboune M (2011) Nicotinic acetylcholine receptor stability at the NMJ deficient in $\alpha$-syntrophin in vivo. J Neurosci 31:1558615596. CrossRef Medline

Missias AC, Mudd J, Cunningham JM, Steinbach JH, Merlie JP, Sanes JR (1997) Deficient development and maintenance of postsynaptic specializations in mutant mice lacking an "adult" acetylcholine receptor subunit. Development 124:5075-5086. Medline

Mouslim C, Aittaleb M, Hume RI, Akaaboune M (2012) A role for the calmodulin kinase II-related anchoring protein $(\alpha \mathrm{kap})$ in maintaining the stability of nicotinic acetylcholine receptors. J Neurosci 32:5177-5185. CrossRef Medline

Nori A, Lin PJ, Cassetti A, Villa A, Bayer KU, Volpe P (2003) Targeting of alpha-kinase-anchoring protein (alpha KAP) to sarcoplasmic reticulum and nuclei of skeletal muscle. Biochem J 370:873-880. CrossRef Medline

O'Leary H, Sui X, Lin PJ, Volpe P, Bayer KU (2006) Nuclear targeting of the CaMKII anchoring protein alpha KAP is regulated by alternative splicing and protein kinases. Brain Res 1086:17-26. CrossRef Medline

Ono F, Higashijima S, Shcherbatko A, Fetcho JR, Brehm P (2001) Paralytic zebrafish lacking acetylcholine receptors fail to localize rapsyn clusters to the synapse. J Neurosci 21:5439-5448. Medline

Ono F, Mandel G, Brehm P (2004) Acetylcholine receptors direct rapsyn clusters to the neuromuscular synapse in zebrafish. J Neurosci 24:54755481. CrossRef Medline

Pires-Oliveira M, Moen D, Akaaboune M (2013) Dynamics of nicotinic acetylcholine receptors and receptor-associated proteins at the vertebrate neuromuscular junction. Curr Alzheimer Res 10:631-641. CrossRef Medline

Sanes JR, Lichtman JW (2001) Induction, assembly, maturation and maintenance of a postsynaptic apparatus. Nat Rev Neurosci 2:791-805. CrossRef Medline

Schmidt N, Akaaboune M, Gajendran N, Martinez-Pena y Valenzuela I, Wakefield S, Thurnheer R, Brenner HR (2011) Neuregulin/ErbB regulate neuromuscular junction development by phosphorylation of alphadystrobrevin. J Cell Biol 195:1171-1184. CrossRef Medline

Scott LJ, Bacou F, Sanes JR (1988) A synapse-specific carbohydrate at the neuromuscular-junction-association with both acetylcholinesterase and a glycolipid. J Neurosci 8:932-944. Medline

Singh P, Salih M, Tuana BS (2009) Alpha-kinase anchoring protein alphaKAP interacts with SERCA2A to spatially position Ca2+/calmodulin-dependent protein kinase II and modulate phospholamban phosphorylation. J Biol Chem 284: 28212-28221. CrossRef Medline

Speese SD, Trotta N, Rodesch CK, Aravamudan B, Broadie K (2003) The ubiquitin proteasome system acutely regulates presynaptic protein turnover and synaptic efficacy. Curr Biol 13:899-910. CrossRef Medline

Turney SG, Culican SM, Lichtman JW (1996) A quantitative fluorescenceimaging technique for studying acetylcholine receptor turnover at neuromuscular junctions in living animals. J Neurosci Methods 64:199-208. CrossRef Medline

Volpe P, Villa A, Podini P, Martini A, Nori A, Panzeri MC, Meldolesi J (1992) The endoplasmic reticulum-sarcoplasmic reticulum connection: distribution of endoplasmic reticulum markers in the sarcoplasmic reticulum of skeletal muscle fibers. Proc Natl Acad Sci U S A 89:6142-6146. CrossRef Medline

Weatherbee SD, Anderson KV, Niswander LA (2006) LDL-receptor-related protein 4 is crucial for formation of the neuromuscular junction. Development 133:4993-5000. CrossRef Medline

Wu H, Xiong WC, Mei L (2010) To build a synapse: signaling pathways in neuromuscular junction assembly. Development 137:1017-1033. CrossRef Medline

Zhang B, Luo S, Wang Q, Suzuki T, Xiong WC, Mei L (2008) LRP4 serves as a coreceptor of agrin. Neuron 60:285-297. CrossRef Medline 